\title{
Modulation of trophism and fiber type gene expression in denervated muscle activated by different patterns of electrical stimulation. Role of muscle fiber regeneration revisited in 2017
}

\author{
${ }^{1}$ IRCCS Fondazione Ospedale San Camillo, Venezia-Lido, Italy \\ ${ }^{2}$ Physiko- und Rheumatherapie Gesllschaft m.b.H., St. Poelten, Austria \\ ${ }^{3}$ Ludwig Boltzmann Institute of Electrical Stimulation and Physical Rehabilitation, Vienna, Austria \\ ${ }^{4}$ Department of Biomedical Sciences, University of Padova, Italy \\ ${ }^{5}$ Anatomy Dept., Southern Illinois University School of Medicine, Carbondale, IL, USA \\ ${ }^{6} \mathrm{Clinical}$ Engineering and Information Technology, Landspitali - University Hospital, Reykjavik, Iceland
}

Andrea Marcante ${ }^{1 *}$, Alfonc Baba ${ }^{1}$, Ugo Carraro ${ }^{1}$, Helmut Kern ${ }^{2,3}$, Stefan Loefler ${ }^{3}$, Christian Hofer ${ }^{3}$, Sandra Zampieri ${ }^{2,3,4}$, Simone Mosole ${ }^{4}$, Pawel Kiper ${ }^{1}$, Simonetta Rossi ${ }^{1}$, Luca Ghezzo ${ }^{1}$, Carla Carollo ${ }^{1}$, Annalena Venneri ${ }^{1}$, Francesco Piccione ${ }^{1}$, Amber Pond ${ }^{5}$ and Paolo Gargiulo $^{6}$

\begin{abstract}
After sixty and more years of basic research on electrostimulation-induced muscle plasticity, in the last fifteen years a few studies have employed long impulse biphasic electrical stimulation as a treatment for human long-term denervated muscle. Tissue trophism and muscle power are improved to a level sufficient to restore some functions by home based Functional Electrical Stimulation (h-bFES). These treatments usually start late after denervation due to clinical constraints. The changes induced by 1) denervation, 2) spontaneous or induced aneural myogenesis, and 3) long-term electrical stimulation starting either early or late after denervation, in both animal models and in clinic, are here reported once again to attract attention of patients, physiatrists and physiotherapists on achievable results and on limitations of h-bFES for denervated degenerating muscles (DDM). The trophic and functional recovery from severe atrophy/degeneration of long-term denervated muscle by h-bFES of DDM is a fact standing on a sound foundation. Furthermore, a new muscle quantitative color computed tomography (MQC-CT) adds, to functional evidence and to muscle biopsy analyses, the results based on tridimensional analysis of a full skeletal muscle. The differentiation of muscle fibers regenerating in the absence of the nerve is remarkable in animal experiments. If myogenesis in patients could be modulated during the months needed to recover denervated muscle tetanic contractility, it should be possible to substantially abbreviate the time needed to achieve functional recovery of long term denervated human muscle by h-bFES of DDM using the commercial muscle stimulator and the large electrodes now available.
\end{abstract}

\section{Introduction}

Sixty years of basic research $[1,2]$ concerning electrostimulationdriven muscle plasticity has, in recent years, prompted clinical trials which investigate the use of long impulse biphasic electrical stimulation as a treatment for human denervated muscle intended to improve tissue trophism and to increase muscle power to a level sufficient to restore standing and step training [3-9]. These treatments usually start late after denervation because of clinical constraints and/or the outdated beliefs that electrical stimulation is useless in these cases and may actually interfere with eventual myofiber reinnervation. These beliefs are still held by some people despite recent evidence that electrostimulation may accelerate nerve growth and proper muscle reinnervation [1013]. Effects of long-term denervation, of spontaneous or induced aneural myogenesis, and of long-term electrical stimulation (starting early or late after denervation) are discussed here. Interrelations of these denervation effects are remarkable and influence trophic and functional recovery from severe atrophy/degeneration of long-term denervated muscle. Their modulation by Home Based Functional Electrical Stimulation (h-bFES) combined with biological approaches may shorten time to recovery and increase functional use of long term denervated human muscles.

\section{Long-term denervation of skeletal muscle}

Permanent denervation of skeletal muscle is followed by early loss of function and late tissue wasting, that is thought to lead to the death of muscle fibers and ultimately to substitution of contractile tissue with adipocytes and collagenous sheets $[8,9,14]$. More specifically, in mammals permanent muscle denervation produces a long-lasting period of denervation atrophy followed after many months by severe atrophy accompanied with lipodystrophy and fibrosis, and also by

Correspondence to: Andrea Marcante, IRCCS Fondazione Ospedale San Camillo Venezia-Lido, Via Alberoni 70, I-30126 Venezia-Lido, Italy; E-mail: Andrea-marcante@ospedale.sancamillo.net

Key words: human denervated muscle; aneural myogenesis; muscle regeneration; Home Based Functional Electrical Stimulation (h-bFES); recovery of tetanic contractility

Received: January 14, 2017; Accepted: February 15, 2017; Published: February 18,2017 
Marcante A (2017) Modulation of trophism and fiber type gene expression in denervated muscle activated by different patterns of electrical stimulation. Role of muscle fiber regeneration revisited in 2017

non-compensatory myogenic events (regeneration of muscle fibers). In the rodent life span (3-4 years), these events start two-four months after permanent denervation and last the entire lifetime, however interspecies differences are significant yet poorly known (see below). All these events are part of the wide range of adaptive responses of muscle tissue, to increased or diminished use, that encompasses the concept of muscle plasticity $[15,16]$.

\section{Severe atrophy}

Muscle atrophy commences early after denervation. This decrease of tissue mass may occur because of a reduction in the size of each myofiber (hypotrophy) and/or loss of myofibers (hypoplasia). We will use "severe atrophy" when hypotrophy reaches a $90 \%$ reduction in myofiber size. It is accompanied by disarray of the sarcomeres which eventually become non-detectable. Chains of myonuclei mark severe atrophy, but hypernucleosis is also present in early myofibers (i.e., in myotubes). An anti-embryonic myosin immuno-stain is necessary and sufficient to distinguish between these two events $[17,18]$. Myonuclear loss and myofiber death could be early events following denervation, while the presence of very thin longitudinal sections devoid of contractile proteins, and having with several-clumped myonuclei along the myofiber, is a marker of long-lasting severe atrophy $[19,20]$. Disruption of molecular mechanisms tethering nuclei to the actin cytoskeleton are possibly responsible for these nuclear events $[21,22]$. On the other hand, these nuclear groups mimic the organization of nuclei at the synapse $[23,24]$, so they may represent an additional mechanism contributing to the long-lasting capacity of aneural myofibers to survive and remain capable of being reinnervated, or even poly-reinnervated, far from their original end plate [25].

\section{Myofiber death}

Cell death and its mechanisms in rodent skeletal muscle undergoing post-denervation atrophy are known in detail [26]. Clear morphological manifestations of muscle cell death, with ultrastructural characteristics very similar, if not identical, to those considered as nuclear and cytoplasmic markers of apoptosis are found. With increasing time from denervation, progressive destabilization of the differentiated phenotype of muscle cells is evidenced by spatial disorganization of myofibrils and formation of myofibril-free zones. These changes initially appear in subsarcolemmal areas near myonuclei, and by 4 -months post denervation, are spread throughout the sarcoplasm. Dead muscle fibers are usually surrounded by a folded intact basal lamina; they have an intact sarcolemma and highly condensed chromatin and sarcoplasm. Folds of the basal lamina around the dead cells result from significant shrinkage of cell volume. Clear manifestations of inflammation are absent in the denervated tissue, yet macrophages are occasionally found in close proximity to dead myocytes.

In rodents, nuclear DNA fragmentation by the TUNEL method, a molecular technique which marks apoptosis, is present in only a very small number of cell nuclei in 2 and 4months post denervated muscle and even to a lesser extent in muscle that has been denervated for 7 months. The numbers of nuclei displaying abnormal morphology (i.e., condensed and/or irregular patterns of chromatin distribution as revealed by DNA staining and electron microscopy), exceed the numbers of nuclei positive for apoptosis (that is, the TUNEL reaction) by $30-40$ fold. In contrast to previous results $[27,28]$, a high discrepancy between the frequency of apoptotic morphological markers and DNA fragmentation seems a peculiar trait of myofiber death in rat denervated muscle.
Muscle degeneration (we will not use the term dystrophy to avoid confusion with muscle genetic diseases) is an even later effect of denervation in which a significant portion of the muscle mass is substituted by different cells, mainly adipocytes (fat degeneration or lipodystrophy) and/or fibroblasts and collagen sheets which surround myofibers (endomysial fibrosis) [29]. These last changes seem to occur in long-term denervated muscle of rat after heavy reduction in the number of capillaries per myofiber [30].

\section{Myogenesis and regeneration of myofibers in denervat- ed skeletal muscles}

Mature mammalian skeletal muscle fibers seem to maintain a relatively finite, fiber type-specific relationship between the size of the myofiber and the number of myonuclei present in a given myofiber [31-33]. However, shortly after birth, mammalian myofibers are permanently differentiated and thus cannot undergo mitotic division or directly increase their nuclear number by myonuclear division. Therefore, myofibers undergoing hypertrophy appear to require an external source of new nuclei to maintain or reestablish a relatively constant myonucleus-to-fiber size ratio. There is a significant body of evidence to suggest that "satellite cells" are the source of new myonuclei in mature mammalian skeletal muscles. Despite some doubts [34], there is also some compelling evidence indicating that satellite cell proliferation is required to support the process of compensatory hypertrophy in mammalian skeletal muscle. Specifically, when high doses of radiation are used in rodents to prevent satellite cell proliferation prior to initiation of skeletal muscle functional overloading, the hypertrophy response is almost absent $[35,36]$.

Surprisingly, evidence of myogenic events is also reported in denervated muscle, i.e., in atrophying skeletal muscles. In contrasts with older reports, light and electron microscopy show that long term denervated muscle maintains a steady-state severe atrophy for the animal life span and that some morphological and molecular features indicate that events of aneural regeneration occur continuously [3739]. New muscle fibers are present as early as one month after nerve section and reach a maximum between 2 and 4 months following denervation of rat leg muscles. Then myogenesis gradually decreases with progressive post-denervation degeneration. These myogenic events occur with permanent long-term denervation and are not related to muscle reinnervation [31].

Muscle partial denervation or reinnervation is a major technical problem in the study of long-term denervated muscle in rodents. The small size of rat legs and the high capacity for peripheral nerve regeneration necessitate careful surgical approaches in establishing the experimental model [30]. Furthermore, minimal residual innervation is the most common event in clinical cases. Research on this "disturbing" variable and of its impact on the h-bFES of long-term denervated human muscles is needed.

The myogenic response in long-term denervated rat muscle is biphasic and includes two distinct processes. The first process resembles the formation of secondary and tertiary generations of myotubes that occurs during normal muscle development and dominates during the first two months post denervation. The activation of this type of myogenic response (myofiber generation, which truly increases the number of myofibers present in an anatomically defined muscle, i.e., hyperplasia) does not depend on cell death and degenerative processes [29].

A second type of myogenesis is a typical regenerative reaction that 
Marcante A (2017) Modulation of trophism and fiber type gene expression in denervated muscle activated by different patterns of electrical stimulation. Role of muscle fiber regeneration revisited in 2017

occurs mainly within the spaces surrounded by the basal lamina of dead muscle fibers [29,38]. Myofibers of different sizes are susceptible to degeneration and death, which indicates that cell death in denervated muscle does not correlate with levels of muscle cell atrophy [29]. These regenerative processes frequently result in the development of abnormal muscle cells that branch or form small clusters surrounded by two layers of basal lamina (the old and the new one, which is secreted by the new myofiber) $[29,38,39]$. Spontaneous myofiber regeneration in long-term denervation has been quantified and shown to be non-compensatory and to result in the reduction of satellite cell pools [29,40-47]. The turnover of myonuclei (but not necessarily of regenerating myofibers), studied by means of continuous infusion of 5- bromo-2-deoxyuridine (BRDU), occurs at most 1 to $2 \%$ per week in adult rats $[45,48]$. Evidence of satellite cell depletion in denervated muscle raises some questions about the long-term potential effects of regenerative myogenesis [41,42]. On the other hand, myotoxicinduced myogenesis speaks in favor of a long-lasting effect (see below).

Interspecies differences raise additional doubts, since there are large differences in post-denervation effects, even in rate of atrophy [49]. In humans, denervation atrophy progresses at a relatively slower rate in comparison to rat, but our observation that the positive myogenic reactions to denervation of human skeletal muscle are very similar to those well described in rodents, is heartening as to the potential application of our work in clinical rehabilitation.

\section{Changes in fiber types and post-denervation switching of muscle genes}

After the fully differentiated pattern of fast and slow myosins has been established in normal adult skeletal muscles, acute denervation has very little influence on the type of contractile proteins synthesized in early atrophying muscle fibers. Preferential atrophy of fast fibers followed by atrophy of slow fibers appears to be the typical feature of the early phases of denervation, producing only a small imbalance in fiber typing [50-52]. However, during several months of permanent denervation there is an almost complete transformation of rat mixed muscles into almost pure fast muscles [38, 53-56], with only low amount of residual slow myosin present with fast myosin in mixed myofibers [38,52]. Analyses of denervated and aneurally regenerated muscles suggest that in long-term denervation of rat soleus the slow-tofast transformation is mainly the consequence of repeated cycles of cell death and regeneration $[43,46,56]$. Such a slow myosin disappearance is less pronounced in other species, $[57,58]$ but it is not known if this means that post-denervation myofiber regeneration is less pronounced.

\section{Induced regenerative myogenesis in long-term denerva- tion}

Beyond traumatic events, regeneration of muscle fibers is studied after induction of muscle damage and regeneration by vitamin E deprivation [35,59], autografting $[29,30]$ or by treatment with myotoxins [60]. Permanent denervation does not prevent induced muscle regeneration [39] and a long-term retention of this capability has been demonstrated in denervated muscles. Specifically, in four-month denervated animals, bupivacaine induces massive and synchronous myofiber regeneration within a few days in both fast and slow rat muscles $[56,61,62]$. When the denervated muscles are treated with marcaine or notexin, autografting of seven-month denervated rat muscles is followed by substitution of old fibers by new fibers $[39,40,42,63,64]$. The aneurally regenerated myofibers grow within a few days post auto-transplantation and maintain the achieved one fourth of their normal adult fiber sizes for two weeks, then they atrophy and reach a steady-state size at less than one tenth of the normal fiber size [39].

When a series of myotoxic injuries are made, leaving time for regeneration to occur between each injury, new muscle fibers form afterward for up to four treatments. This provides evidence that some of the proliferating satellite cells reenter an undifferentiated, stem cell-like state, being capable of myogenesis after further injuries to the muscle $[65,66]$.

Satellite cell proliferation and myofiber regeneration is enhanced in long-term denervated muscles when they are subjected to electrical stimulation $[67,68]$. This is not surprising since satellite cell proliferation is increased in normal muscle by increased physical activity, in particular strength training [69], but also by massage [70].

\section{Electrical stimulation of denervated muscles}

\section{Applied immediately after denervation electrical stimulation induces fiber type switching}

Mammalian skeletal muscle is primarily composed of twitch fibers, which are grouped into two major physiological classes based on their speeds of contraction and relaxation. Although these general categories can be broadly applied, there is a spectrum of contraction and relaxation speed with a wide variety of types including specialized extremes and intermediate forms present in various muscles. The fast and slow fibers express different isoforms of myosins and of other contractile proteins [71] which concur to determine their contraction-relaxation speed. Furthermore, they have different concentrations of the proteins controlling activation and relaxation processes (i.e. of $\mathrm{Ca}^{2+}$ handling proteins) and of many metabolic enzymes [15,16]. Transitional fibers are frequently seen and reflect the dynamic remodelling of skeletal muscle tissue based upon its in vivo physiological use and the plasticity of fiber types, $[15,16,72,73]$ including the case of electrical stimulation of innervated and denervated muscles [74,75].

It is well established in animals that changes of muscle stimulation patterns produce variation in levels of fiber type-specific muscle protein isoforms, but such changes in protein composition take weeks to occur because of the relatively slow turnover of most muscle contractile proteins [72].

The time course of changes in muscle gene expression, monitored at the transcript level, is more rapid than that of changes at the protein level during chronic in vivo muscle stimulation in animals [76]. An increase in the slow fiber MHC mRNA has been demonstrated in the stimulated whole muscle of living animals [6] and in culture [78], as well as in single muscle fibers electrostimulated in vitro [79]. The last two studies are conclusive evidence that not only is muscle fiber development independent from direct contact with the motoneurons, but also that the influence of motoneuron activity on muscle plasticity could be at least in part mimicked by different patterns of electrical stimulation both in vivo and in vitro (for a detailed review see [80]).

The contractile phenotype of muscle fibers is under control of hormones, as well as stretch and influences from the motoneurons. Motoneurons can affect muscle fibers by releasing neurotrophic substances and by evoking electrical activity in the muscle. For regulating contractile properties such as speed, strength and endurance it has been demonstrated that the signal to change is coded in the pattern of electrical activity. Thus, high amounts of activity lead to slow shortening velocity and synthesis of slow myosin, [71,72], while low 
Marcante A (2017) Modulation of trophism and fiber type gene expression in denervated muscle activated by different patterns of electrical stimulation. Role of muscle fiber regeneration revisited in 2017

amounts of activity lead to a fast phenotype [81-84]. Even slow myosin heavy chains could be expressed in denervated fast myofibers by slowlike continuous electrostimulation [85-87].

On the other hand, there appear to be some restrictions on the extent to which myofiber characteristics of denervated muscle will undergo transformation in response to electrical stimulation $[71,75]$. In a typical study, the slow soleus muscle and the fast EDL were denervated and immediately stimulated directly with implanted electrodes for up to 82 days. Four different stimulation patterns were used to mimic natural motor-unit activities in these muscles [88-90]. Native stimulation patterns maintain normal contractile speed, but in the EDL, normal isotonic shortening velocity was maintained only by a stimulation pattern consisting of very brief trains with an initial short interspike interval (a doublet), and not by the other native highfrequency patterns. The results indicate that for the control of contractile properties instantaneous frequency, total amount of stimulation, train length, interval between trains and presence of an initial doublet ought to be taken into account. Changes in contractile speed induced by a foreign stimulation pattern were quantitatively similar to the effects of cross-innervation both in the EDL and the soleus. Thus, the change in activity pattern is the mechanism behind most of the changes induced by cross- innervation [88].

Nonetheless, others report negative results in guinea pig [91]. When guinea-pig soleus muscles were denervated and electrically stimulated for periods up to two months by stimuli consisting of $1 \mathrm{~s}$ bursts of 40 $\mathrm{Hz}$ pulses, repeated every $5 \mathrm{~min}$ (a chronic phasic stimulation that produces quickening of contractile properties in denervated soleus rat muscle) the fast conversion is not attained as expected. Since myotoxic injury of this slow muscle produces new myofibers as fast as those seen in rat experiments, the data are compatible with the hypothesis that slow-to-fast transformation of denervated rat soleus is not directly brought about by chronic stimulation but by de-novo formation of fast-contracting regenerated fibers $[43,46]$. It remains to be explained why myofibers of guinea pig soleus rarely undergo denervation-evoked death and regeneration in comparison to rat soleus. The persistence of fibrillation in guinea-pig but not rat after denervation may account for the species difference [91]. Similar interspecies discrepancies are also known when normal muscle is indirectly electrostimulated through its motor nerve [92].

Note: When human muscles are discussed, the reader should be ready to accept some discrepancies in results in comparison to the more often used rodent animal models.

\section{Muscle trophism}

For preventing decrease of muscle mass and of myofiber size (i.e., atrophy) in denervated muscles high frequency pulses seem to be beneficial, particularly in fast muscles. $[93,94]$. In denervated muscles the results mimic the well-known efficacy of high frequency electrical stimulation to induce skeletal muscle hypertrophy [95], and of low frequency electrical stimulation protocol to induce endurancelike adaptations when applied 5 days/week for 3 weeks $[81,96,97]$. Recent evidence shows that trophism and fiber type are regulated independently through different transduction signaling pathways [98101]. The role of putative neurotrophic substances remains unclear, with the exception of the release of neuronal agrin and other growth factors, which are relevant in modulating neuromuscular junctions [102].

Though still criticized by the medical community (due to inexperience within the proper methodology), electrical stimulation applied early after nerve injury maintains trophism of denervated muscle or at least delays the process [100-102].

\section{Electrical stimulation applied later after denervation}

A few relevant publications concern the restorative effects of electrical currents activating long-term denervated muscles in animal models $[74,106,107]$. Intermittent electrical stimulation at $100 \mathrm{~Hz}$ (one train of 60 pulses every minute) either maintains (by early stimulation) or restores in two months the force output to nearly normal values when stimulation starts at two, four or even nine months after sciatectomy of rat leg [74,75]. Long-term stimulation causes similar increases in muscle fiber cross sectional area in fast and slow muscles, and changes are identical when innervated muscles are stimulated in the same way [74].

Muscle residual innervation or reinnervation is a major technical problem in the study of long-term denervated muscle in rodents. The small size of rat legs and their high capacity to regenerate peripheral nerves requires the use of careful surgical approaches in establishing the experimental model [31]. On the other hand, clinical minimal residual innervation is the most common case [108], and research on this "disturbing" effect is also needed. The innervated myofibers responding well to electrostimulation may discourage the use of the current intensity needed to activate the aneural regenerated or atrophic myofibers intermixed with the innervated/reinnervated muscle fibers.

\section{Home based functional electrical stimulation (h-bFES) of long- term denervated human muscles}

Over the last 30 years there has been a good deal of interest in the use of h-bFES to restore movement to the limbs of patients immobilized by spinal-cord injury (upper motor neuron lesion, spastic paralysis) [109-111]. There is, however, another group of patients whose problems are more difficult to treat. Persons suffering with complete Conus and Cauda Equina syndrome present with severe secondary medical problems because of the marked atrophy of denervated muscles and the associated loss of bone mass and skin dystrophy [1]. In these patients injury also results in irreversible loss of the nerve supply to some or all of the affected limbs (flaccid paralysis due to lower motor neuron lesion). It is technically more difficult to treat these patients because direct stimulation of muscles requires more electrical energy than commercially available stimulation devices can deliver. The absence of functional nerve fibers makes it more difficult to recruit a sufficient population of myofibers to regain functional movements at an acceptable force level by surface electrodes. Despite these difficulties, pilot studies of the functional clinical application of FES to denervated muscles have been published. One study has demonstrated gait correction occurs after direct FES of the denervated tibialis anterior muscle [105]. Many others [3-9], contrary to widely accepted opinion, have shown that electrical stimulation can restore muscle mass and force production subsequent to the recovery of sustained muscle contractions. Indeed, through the successful EU Program: RISE [Use of electrical stimulation to restore standing in paraplegics with long-term denervated degenerated muscles (QLG5CT-2001-02191), we have demonstrated, that Home Based Functional Electrical Stimulation (h-bFES) therapy improves the muscle quality of mobility impaired persons, even in the extreme case of postdenervation muscle degeneration [4-9,13]. In complete Conus and Cauda Equina syndrome, a spinal cord injury (SCI) sequelae in which the leg muscles are completely disconnected from the nervous system, 
Marcante A (2017) Modulation of trophism and fiber type gene expression in denervated muscle activated by different patterns of electrical stimulation. Role of muscle fiber regeneration revisited in 2017

affected muscle undergoes sequential stages of loss of function and then, finally, complete loss of skeletal muscle tissue. Analyzing muscle tissue harvested from RISE patients at different time points after SCI, we discovered that: a) loss of stimulation-induced contractility leads to ultrastructural disorganization within months; b) progressive atrophy persists for up to 2-years after SCI; and c) substantial loss of myofibers appears more than 3 years after SCI. Furthermore, we have shown that home-based functional electrical stimulation (h-bFES) of denervated muscles can inhibit muscle loss and also recover muscle from degeneration. Interestingly, functional data are strongly correlated to histo-morphometric results [9]. Conclusive evidence of the efficacy and necessity of home-based (h-b) FES is the fact that once h-bFES-induced recovery is obtained, its discontinuation results in degeneration of the leg muscles [112]. Furthermore, its effectiveness can be maintained over time. After a cross-sectional study, had shown that long-standing denervated muscles were rescued by home-based functional electrical stimulation (h-bFES) training [3], we confirmed those interesting results by a 2-year longitudinal prospective study of 25 patients with complete conus/cauda equina lesions [9]. Denervated leg muscles were stimulated by h-bFES using a customdesigned stimulator and large surface electrodes. Muscle mass, force, and structure were determined before and after 2 years of h-bFES using computed tomography, measurements of knee torque during stimulation, and muscle biopsies analyzed by histology and electron microscopy. Twenty out of 25 patients completed the 2 -year h-bFES program, which resulted in: (a) a 35\% cross-sectional increase in area of the quadriceps $(P<.001)$; (b) a $75 \%$ increase in mean diameter of muscle fibers $(P<.001)$; and (c) improvements of the ultrastructural organization of contractile material. Furthermore a $1187 \%$ increase in force output during electrical stimulation $(P<.001)$ was achieved. The recovery of quadriceps force was sufficient to allow $25 \%$ of the subjects to perform FES-assisted stand-up exercises, demonstrating that h-bFES of denervated muscle is an effective home therapy that results in rescue of tetanic contractility and muscle mass [9]. Important immediate benefits for the patients were the improved cosmetic appearance of lower extremities and the enhanced cushioning effect for seating. Interestingly, immunohistochemistry for anti-embryonic MHC shown that regenerating myofibers were present in all the muscle biopsies. Some myofibers had central nuclei, a feature suggesting they regenerated no more than 10-days before muscle biopsy harvesting. Frequency distribution of myofibers according to their minimum diameter in semi-thin sections shows that about $50 \%$ were severely atrophic (minimum diameter smaller than $10 \mu \mathrm{m}$ ), but a large proportion of myofibers were eutrophic or hypertrophic, i.e., with a minimum diameter larger than $40 \mu \mathrm{m}$.

These results were substantiated by structure to function correlations and by an advanced clinical muscle imaging technique, i.e., Quantitative Muscle Color - Computed Tomography (QMC-CT) [9].

\section{Quantitative computed tomography and image analysis for advanced muscle assessment}

The growing field of translational myology continually seeks to define and promote the application of muscle research to clinical practice by optimizing the transition of a wide variety of investigative muscle assessment modalities. Medical imaging is of particular interest in this regard, as the extant literature focuses on utilization of a wide variety of techniques to non-invasively recapitulate and quantify various internal and external tissue morphologies. In the clinical context, medical imaging remains a vital field of research for diagnostic and investigative assessment. Of the many facets of medical imaging, the most current research aspires to improve aspects of instrumentation design, image processing software, data acquisition methodology, and computational modeling. In particular, methods that enable the $3 \mathrm{D}$ visualization of internal anatomy elicit valuable information for optimizing the treatment of many pathologies, but every modality has its inherent limitations. For the purposes of clinical assessment, in particular, visually simplistic imaging methods with high-resolution for assessing diseased or damaged tissues have readily been identified as a strategic priority in translational myology research [113].

It is known that skeletal muscle deteriorates in response to nerve or muscle damage, prolonged bed rest, diseases such as sepsis, and with normal aging [114]. The follow-up of muscle atrophy/degeneration in neuro-muscularly traumatized people is difficult because of the lack of adequate imaging analyses and also the practical and ethical constraints on harvesting the muscle biopsies necessary to monitor the efficacy of the therapy/rehabilitation strategies. Spiral or Multilayer Computed Tomography (CT) approaches may be performed presently, but these do not yet have the necessary sensitivity to quantitate anatomically defined human skeletal muscles. The need to modify therapeutic interventions to improve muscle retention/recovery in mobility impaired patients is emerging from the literature along with the obvious need for improved assessment methods. Clinical studies, supported by studies of animal models, demonstrate that a moderate program of physical therapy has positive effects. Nevertheless, the human data are inconclusive and poorly disseminated because of the sampling limitations inherent to human studies. Obviously, a more sensitive method for quantitative clinical imaging of skeletal muscle is needed to improve physicians' ability to assess the condition of skeletal muscle and, thus, their ability to design rehabilitation managements. False Color Computed Tomography is popular in cardiology [115], but QMC-CT is still a novelty for quantitative analyses of total volume and quality of anatomically defined skeletal muscles. QMC-CT is a highly sensitive quantitative imaging analysis recently developed by the group of Prof. Paolo Gargiulo to monitor skeletal muscle and perform follow-up examinations of muscle affected by wasting conditions [116-120]. Through the successful EU Program: RISE [Use of electrical stimulation to restore standing in paraplegics with longterm denervated degenerated muscles (QLG5-CT-2001-02191), and INTERREG III and IV: European Regional Development Fund, project Mobilität im Alter, MOBIL, N_00033)], we have demonstrated, mainly through the use of QMC-CT, that h-bFES therapy improves the muscle quality of mobility impaired persons [9] and of healthy seniors [114].

QMC-CT uses CT numbers, i.e., Hounsfield Units (HU), for tissue characterization. In the process of assessing muscle quality, it allows for discrimination of soft tissues as follows: subcutaneous fat, intramuscular fat, low density muscle, normal muscle, and fibrousdense connective tissue. To further evaluate this data, pixels within the defined interval of $\mathrm{HU}$ values (or, more generally, gray values when these data are not from CT scans) are selected and highlighted, while others with $\mathrm{HU}$ values outside the threshold remain black. Soft tissues are divided and colored as follows: subcutaneous fat (yellow: -200 to -10 $\mathrm{HU}$ ), intramuscular fat (orange: -200 to $-10 \mathrm{HU}$ ), low density muscle (cyan: -9 to $40 \mathrm{HU}$ ), normal muscle (red: 41 to $70 \mathrm{HU}$ ) and fibrousdense connective tissue (gray: 71 to $150 \mathrm{HU}$ ). Soft tissue discrimination in a leg and its quantitation can be achieved. The Hounsfield values for the entirety of the lower limbs can be plotted on a histogram to display the tissues profiles. 
Marcante A (2017) Modulation of trophism and fiber type gene expression in denervated muscle activated by different patterns of electrical stimulation. Role of muscle fiber regeneration revisited in 2017

However, we suggest there is a need to further validate QMC-CT to improve diagnosis and follow-up of mobility impaired patients, taking advantage of its sensitivity to recognize minor quantitative changes eventually induced by conventional physical therapy and FES.

\section{Perspective}

After sixty years of basic research concerning electrostimulationinduced muscle plasticity, Functional Electrical Stimulation by means of long biphasic impulses is able to restore muscle mass, force production and movement after long-lasting complete denervation. Patients suffering from flaccid paraplegia (denervation of lower extremity muscles, conus cauda syndrome) are especially good candidates for these approaches [9].

In the long term, we may consider the development and application of implantable solutions as alternatives to the actual approaches based on surface electrodes. Before this could be taken into consideration for those patients, whose residual innervation elicits painful sensation, a better knowledge and control of stimulation-induced muscle trophism should be achieved. Then, artificial synapses, i.e. a pool of miniaturized electrodes, which contact each of the surviving or regenerated myofibers in the denervated muscle, have to be designed and developed. Taking advantage of the powerful angiogenesis of regenerating muscle [70], one may consider that the sacrifice of some of the new vascular branches might be worth development of the ability to deliver sufficient current to new myofibers by means of nanofabricated electrodes.

For now, based on pilot human studies and the application of existing experimental knowledge, it can be anticipated that FES of longterm denervated muscles by surface electrodes will improve mobility with substantial reductions in the risk and the severity of secondary medical problems, resulting in less frequent hospitalizations and a reduced burden on public health services. Integrating h-bFES training with nutritional and volitional In-Bed Gym taken-home strategies, [121], the patients will look forward to improved health, independence and quality of life, and the prospects of better professional and social integration.

\section{Acknowledgement}

Supported by Italian Ministero per l'Università e la Ricerca Scientifica e Tecnologica (M.U.R.S.T.); The EU Commission Shared Cost Project RISE (Contract no. QLG5-CT-2001-02191) and the Austrian Ministry of Science, and The Ludwig Boltzmann Society (Vienna). U. Carraro thanks the IRCCS Fondazione Ospedale San Camillo, Venice (Italy) for scientific support and hospitality.

\section{References}

1. Kern H, Carraro U (2014) Home-based Functional Electrical Stimulation (h-b FES) for long-term denervated human muscle: History, basics, results and perspectives of the Vienna Rehabilitation Strategy. Eur J Transl Myol 24: 27-40. [Crossref]

2. Carraro U, Kern H, Gava P, Hofer C, Loefler S, et al. (2016) Recovery from muscle weakness by exercise and FES: lessons from Masters, active or sedentary seniors and SCI patients. Aging Clin Exp Res. [Crossref]

3. Kern H, Boncompagni S, Rossini K, Mayr W, Fanò G, et al. (2004) Long-term denervation in humans causes degeneration of both contractile and excitationcontraction coupling apparatus that can be reversed by functional electrical stimulation (FES). A role for myofiber regeneration? J Neuropathol Exp Neurol 63: 919-931. [Crossref]

4. Kern H, Rossini K, Carraro U, Mayr W, Vogelauer M, et al. (2005) Muscle biopsies show that FES of denervated muscles reverses human muscle degeneration from permanent spinal motoneuron lesion. J Rehabil Res Dev 42: 43-53. [Crossref]

5. Carraro U, Rossini K, Mayr W, Kern H (2005) Muscle fiber regeneration in human permanent lower motoneuron denervation: relevance to safety and effectiveness of FES-training, which induces muscle recovery in SCI subjects. Artif Organs 29: 187191. [Crossref]

6. Kern H, Salmons S, Mayr W, Rossini K, Carraro U (2005) Recovery of long-term denervated human muscles induced by electrical stimulation. Muscle Nerve 31: 98101. [Crossref]

7. Boncompagni S, Kern H, Rossini K, Hofer C, Mayr W, et al. (2007) Structural differentiation of skeletal muscle fibers in the absence of innervation in humans. Proc Natl Acad Sci U S A 104: 19339-19344. [Crossref]

8. Kern H, Carraro U, Adami N, Hofer C, Loefler S (2010) One year of home-based Functional Electrical Stimulation (FES) in complete lower motor neuron paraplegia: Recovery of tetanic contractility drives the structural improvements of denervated muscle. Neurol Res 32: 5-12. [Crossref]

9. Kern H, Carraro U, Adami N, Biral D, Hofer C, et al. (2010) Home-based functional electrical stimulation rescues permanently denervated muscles in paraplegic patients with complete lower motor neuron lesion. Neurorehabil Neural Repair 24: 709-721. [Crossref]

10. Zealear DL, Rodriguez RJ, Kenny T, Billante MJ, Cho Y (2002) Electrical Stimulation of a Denervated Muscle Promotes Selective Reinnervation by Native Over Foreign Motoneurons. J Neurophysiol 87: 2195-2199. [Crossref]

11. Willand MP (2015) Electrical Stimulation Enhances Reinnervation After Nerve Injury. Eur J Transl Myol 25: 243-248. [Crossref]

12. Willand MP, Nguyen MA, Borschel GH, Gordon T (2016) Electrical Stimulation to Promote Peripheral Nerve Regeneration. Neurorehabil Neural Repair 30: 490-496. [Crossref]

13. Willand MP, Rosa E, Michalski B, Zhang JJ, Gordon T (2016) Electrical muscle stimulation elevates intramuscular BDNF and GDNF mRNA following peripheral nerve injury and repair in rats. Neuroscience 334: 93-104. [Crossref]

14. Gutmann E (1962) (Ed): The denervated muscle. Prague, Publishing House of Czechoslovak Academy of Science, 1-371.

15. Pette D (1980) Plasticity of Muscle. Berlin New York: de Gruyter.

16. Dirk Pette, Gerta Vrbová (2017) The Contribution of Neuromuscular Stimulation in Elucidating Muscle Plasticity Revisited. Eur J Transl Myol 27: 33-39.

17. Rossini K, Sandri M, Rizzi C, Destro C, Dell'Aica I, et al. (1999) Molecular markers of muscle plasticity, damage, regeneration and repair. Basic Appl Myol 9: 293-300.

18. Rossini K, Zanin ME, Carraro U (2002) To stage and quantify regenerative myogenesis in human long-term permanent denervated muscle. Basic Appl Myol 12: 277-287.

19. Viguie CA, Lu DX, Huang SK, Rengen H, Carlson BM (1997) Quantitative study of the effects of long-term denervation on the extensor digitorum longus muscle of the rat. Anat Rec 248: 346-354. [Crossref]

20. Carraro U, Kern H (2016) Severely Atrophic Human Muscle Fibers with Nuclear Misplacement Survive Many Years of Permanent Denervation. Eur J Transl Myol 26: 5894. [Crossref]

21. Reinsch S, Gönczy P (1998) Mechanisms of nuclear positioning. J Cell Sci 111: 2283 2295. [Crossref]

22. Starr DA, Han M (2002) Role of ANC-1 in tethering nuclei to the actin cytoskeleton Science 298: 406-409. [Crossref]

23. Grady RM, Starr DA, Ackerman GL, Sanes JR, Han M (2005) Syne proteins anchor muscle nuclei at the neuromuscular junction. Proc Natl Acad Sci U SA 102: 4359-4364. [Crossref]

24. Cadot B, Gache V, Gomes ER (2015) Moving and positioning the nucleus in skeletal muscle - one step at a time. Nucleus 6: 373-381. [Crossref]

25. Salviati G, Biasia E, Aloisi M (1986) Synthesis of fast myosin induced by fast ectopic innervation of rat soleus muscle is restricted to the ectopic endplate region. Nature 322: 637-639.

26. Borisov AB, Carlson BM (2000) Cell death in denervated skeletal muscle is distinct from classical apoptosis. Anat Rec 258: 305-318. [Crossref]

27. Migheli A, Mongini T, Doriguzzi C, Chiado-Piat L, Piva R, et al. (1997). Muscle apoptosis in humans occurs in normal and denervated muscle, but not in myotonic dystrophy, dystrophinopathies or inflammatory disease. Neurogenetics 1: 81-87.

28. Tews DS, Goebel HH, Schneider I, Gunkel A, Stennert E, et al. (1997) DNAfragmentation and ex- pression of apoptosis-related proteins in experimentally 
Marcante A (2017) Modulation of trophism and fiber type gene expression in denervated muscle activated by different patterns of electrical stimulation. Role of muscle fiber regeneration revisited in 2017

denervated and reinnervated rat facial muscle. Appl Neurobiol 23: 141-149

29. Borisov AB, Dedkov EI, Carlson BM (2001) Interrelations of myogenic response, progressive atrophy of muscle fibers, and cell death in denervated skeletal muscle. Anat $\operatorname{Rec} 264:$ 203-218. [Crossref]

30. Carlson BM, Borisov AI, Dekov EI, Dow D, Kostrominova TY (2002) The biology and restorative capacity of long-term denervated skeletal muscle. Basic Appl Myol 12: 247-254.

31. Allen DL, Monke SR, Talmadge RJ, Roy RR, Edgerton VR (1995) Plasticity of myonuclear number in hypertrophied and atrophied mammalian skeletal muscle fibers. J Appl Physiol (1985) 78: 1969-1976. [Crossref]

32. Cheek DB, Holt AB, Hill DE, Talbert JL (1971) Skeletal muscle mass and growth: the concept of the deoxy- ribonucleic acid unit. Pediatric Research 5: 312-328.

33. Hikida RS, Van Nostran S, Murray JD, Staron RS, Gordon SE, et al. (1997) Myonuclear loss in atrophied soleus muscle fibers. Anat Rec 247: 350-354. [Crossref]

34. Gundersen K, Bruusgaard JC (2008) Nuclear domains during muscle atrophy: nuclei lost or paradigm lost? J Physiol 586: 2675-2681. [Crossref]

35. Aloisi M (1970) Patterns of muscle regeneration, in Mauro A, Shafiq SA, Milhorat AT (Eds): Regeneration of striated muscles and myogenesis. Amsterdam, Excerpata Medica 180-193.

36. Yablonka-Reuveni Z (2011) The skeletal muscle satellite cell: still young and fascinating at 50. J Histochem Cytochem 59: 1041-1059. [Crossref]

37. Carraro U, Dalla Libera L, Catani C (1983) Myosin light and heavy chains in muscle regenerating in absence of the nerve: transient appearance of the embryonic light chain. Exp Neurol 79: 106-117. [Crossref]

38. Carraro U, Morale D, Mussini I, Lucke S, Cantini M, et al. (1985) Chronic denervation of rat diaphragm: maintenance of fiber heterogeneity with associated increasing uniformity of myosin isoforms. J Cell Biol 100: 161-174. [Crossref]

39. Mussini I, Favaro G, Carraro U (1987) Maturation, dystrophic changes and the continuous production of fibers in skeletal muscle regenerating in the absence of nerve. J Neuropathol Exp Neurol 46: 315-331. [Crossref]

40. Billington L, Carlson BM (1996) The recovery of long-term denervated rat muscles after Marcaine treatment and grafting. J Neurol Sci 144: 147-155. [Crossref]

41. Dedkov EI, Kostrominova TY, Borisov AB, Carlson BM (2001) Reparative myogenesis in long-term denervated skeletal muscles of adult rats results in a reduction of the satellite cell population. Anat Rec 263: 139-154. [Crossref]

42. Jejurikar SS, Marcelo CL, Kuzon WM Jr. (2002) Skeletal muscle denervation increases satellite cell susceptibility to apoptosis. Plast Reconstr Surg 110: 160-168. [Crossref]

43. Lewis DM, Schmalbruch H (1994) Contractile properties of aneurally regenerated compared with denervated muscles of rat. J Muscle Res Cell Motil 15: 267-277. [Crossref]

44. Lewis DM, Schmalbruch H (1995) Effects of age on aneural regeneration of soleus muscle in rat. $J$ Physiol 488: 483-492. [Crossref]

45. Rodrigues Ade C, Schmalbruch H (1995) Satellite cells and myonuclei in long-term denervated rat muscles. Anat Rec 243: 430-437. [Crossref]

46. Schmalbruch H, Lewis DM (1994) A comparison of the morphology of denervated with aneurally regenerated soleus muscle of rat. J Muscle Res Cell Motil 15: 256-266. [Crossref]

47. Yoshimura K, Harii K (1999) A regenerative change during muscle adaptation to denervation in rats. J Surg Res 81: 139-146. [Crossref]

48. Schmalbruch H, Lewis DM (2000) Dynamics of nuclei of muscle fibers and connective tissue cells in normal and denervated rat muscles. Muscle Nerve 23: 617-626. [Crossref]

49. Hnik P (1962) Rate of denervation muscle atrophy, in Gutmann E (Ed): The denervated muscle. Prague, Publishing House of Czechoslovak Academy of Science 341-371.

50. Jakubiec-Puka A, Kordowska J, Catani C, Carraro U (1990) Myosin heavy chain isoform composition in striated muscle after denervation and self-reinnervation. Eur $J$ Biochem 193: 623-628. [Crossref]

51. Pette D (2001) Historical Perspectives: plasticity of mammalian skeletal muscle. J App Physiol (1985) 90: 1119-1124. [Crossref]

52. Talmadge RJ, Roy RR, Bodine-Fowler SC, Pierotti DJ, Edgerton VR (1995) Adaptations in myosin heavy chain profile in chronically unloaded muscles. Basic Appl Myol 5: 117-137. [Crossref]
53. Carraro U, Catani C, Biral D (1979) Selective maintenance of neurotrophically regulated proteins in denervated rat diaphragm. Exp Neurol 63: 468-475. [Crossref]

54. Carraro U, Catani C, Dalla Libera L (1981) Myosin light and heavy chains in rat gastrocnemius and diaphragm muscles after chronic denervation or reinnervation. Exp Neurol 72: 401-412. [Crossref]

55. Carraro U, Dalla Libera L, Catani C, Danieli-Betto D (1982) Chronic denervation of rat diaphragm: selective maintenance of adult fast myosin heavy chains. Muscle Nerve 5: 515-524. [Crossref]

56. Carraro U, Catani C, Degani A, Rizzi C (1990) Myosin expression in denervated fastand slow-twitch muscles: Fiber modulation and substitution, in Pette D (Ed): The dynamic state of muscle fibers. Berlin, New York, Walter de Gruyter 247-262.

57. Gauthier GF, Hobbs AW (1982) Effects of denervation on the distribution of myosin isozymes in skeletal muscle fibers. Exp Neurol 76: 331-346. [Crossref]

58. Bacou F, Rouanet P, Barjot C, Janmot C, Vigneron P, et al. (1996) Expression of myosin isoforms in denervated, cross-reinnervated, and electrically stimulated rabbit muscles. Eur J Biochem 236: 539-547. [Crossref]

59. Gallucci V, Novello F, Margreth A, Aloisi M (1966) Biochemical correlates of discontinuous muscle regeneration in rat. Br J Exp Pathol 47: 215-227. [Crossref]

60. Carraro U, Catani C (1983) A sensitive SDS PAGE method separating heavy chain isoforms of rat skeletal muscles reveals the heterogeneous nature of the embryonic myosin. Biochem Biophys Res Commun 116: 793-802.

61. Carraro U, Rossini K, Zanin ME (2002) Muscle stem cells and recovery of function by electrical stimulation of permanent denervated, regenerated muscle. International FES Society 402-404.

62. Carraro U, Rossini K, Zanin ME, Rizzi C, Mayr W, et al. (2002) Induced myogenesis in long-term permanent denervation: perspective role in Functional Electrical Stimulation of denervated legs in humans. Basic Appl Myol 12: 53-64.

63. Gulati AK (1988) Long-term retention of regenerative capability after denervation of skeletal muscle, and dependency of late differentiation on innervation. Anat Rec 220: 429-434. [Crossref]

64. Lu DX, Huang SK, Carlson BM (1997) Electron microscopic study of long-term denervated rat skeletal muscle. Anat Rec 248: 355-365. [Crossref]

65. Gross JG, Morgan JE (1999) Muscle precursor cells injected into irradiated mdx mouse muscle persist after serial injury. Muscle Nerve 22: 174-185. [Crossref]

66. Gross JG, Bou-Gharios G, Morgan JE (1999) Potentiation of myoblast transplantation by host muscle irradiation is dependent on the rate of radiation delivery. Cell Tissue Res 298: 371-375. [Crossref]

67. Mussini I, Calliari I, Marchioro L, Vianello F, Gobbo V, et al. (1988) Morphologica changes of muscle fiber and neuromuscular junction following electrostimulation, in Carraro U (ed): Sarcomeric and non-sarcomeric muscles: basic and applied research prospects for the 90's. Padova, Unipress Padova, 391-402.

68. Putman CT, Düsterhöft S, Pette D (2000) Satellite cell proliferation in low frequency stimulated fast muscle of hypothyroid rat. Am J Physiol Cell Physiol 279: C682-690. [Crossref]

69. Kadi F, Schjerling P, Andersen LL, Charifi N, Madsen JL, et al. (2004) The effects of heavy resistance training and detraining on satellite cells in human skeletal muscles. $J$ Physiol 558: 1005-1012. [Crossref]

70. Best TM, Gharaibeh B, Huard J (2013) Stem cells, angiogenesis and muscle healing: a potential role in massage therapies? Br J Sports Med 47: 556-560. [Crossref]

71. Schiaffino S, Reggiani C (1996) Molecular diversity of myofibrillar proteins: gene regulation and functional significance. Physiol Rev 76: 371-423. [Crossref]

72. Pette D, Vrbová G (1992) Adaptation of mammalian skeletal muscle fibers to chronic electrical stimulation. Rev Physiol Biochem Pharmacol 120: 115-202. [Crossref]

73. Williams RS, Garcia-Moll M, Mellor J, Salmons S, Harlan W (1987) Adaptation of skeletal muscle to increased contractile activity. Expression nuclear genes encoding mitochondrial proteins. J Biol Chem 262: 2764-2767. [Crossref]

74. Lømo T, Westgaard RH, Hennig R, Gundersen K (1985) The response of denervated muscle to long-term electrical stimulation, in Carraro U, Angelini C, (Eds): Cell Biology and Clinical Management in Functional Electro Stimulation of Neurons and Muscles. Padova, Italy, CLEUP Editore, 81-90.

75. Lomo T (2014) The Response of Denervated Muscle to Long-Term Stimulation (1985, Revisited here in 2014). Eur J Transl Myol 24: 3294. [Crossref] 
Marcante A (2017) Modulation of trophism and fiber type gene expression in denervated muscle activated by different patterns of electrical stimulation. Role of muscle fiber regeneration revisited in 2017

76. Williams RS, Garcia-Moll M, Mellor J, Salmons S, Harlan W (1987) Adaptation of skeletal muscle to increased contractile activity. Expression nuclear genes encoding mitochondrial proteins. $J$ Biol Chem 262: 2764-2767. [Crossref]

77. Brownson C, Little P, Jarvis JC, Salmons S (1992) Reciprocal changes in myosin isoform mRNAs of rabbit skeletal muscle in response to the initiation and ces-sation of chronic electrical stimulation. Muscle Nerve 15: 694-700. [Crossref]

78. Barton-Davis ER, LaFramboise WA, Kushmerick MJ (1996) Activity-dependen induction of slow myosin gene expression in isolated fast-twitch mouse muscle. $\mathrm{Am} \mathrm{J}$ Physiol 271: C1409-1414. [Crossref]

79. Liu Y, Schneider MF (1998) Fibre type-specific gene expression activated by chronic electrical stimulation of adult mouse skeletal muscle fibres in culture. J Physiol 512: 337-344. [Crossref]

80. Gundersen K (1998) Determination of muscle contractile properties: the importance of the nerve. Acta Physiol Scand 162: 333-341. [Crossref]

81. Salmons S, Henriksson J (1981) The adaptive response of skeletal muscle to increased use. Muscle Nerve 4: 94-105. [Crossref]

82. Carraro U, Catani C, Saggin L, Zrunek M, Szabolcs M, et al. (1988) Isomyosin changes after functional electrostimulation of denervated sheep muscle. Muscle Nerve 11: 10161028. [Crossref]

83. Arpesella G, Carraro U, Mikus PM, Dozza F, Lombardi P, et al. (1998) Activity-res stimulation of latissimus dorsi for cardiomyoplasty: 1-year results in sheep. Ann Thorac Surg 66: 1983-1990. [Crossref]

84. Carraro U, Barbiero M, Docali G, Cotogni A, Rigatelli G, et al. (2000) Demand dynamic cardiomyoplasty: mechanograms prove incomplete transformation of the rested latissimus dorsi. Ann Thorac Surg 70: 67-73. [Crossref]

85. Carraro U, Catani C, Belluco S, Cantini M, Marchioro L (1986) Slow-like electrostimulation switches on slow myosin in denervated fast muscle. Exp Neurol 94 : 537-553. [Crossref]

86. Mayne CN, Mokrusch T, Jarvis JC, Gilroy SJ, Salmons S (1993) Stimulation-induced expression of slow muscle myosin in a fast muscle of the rat. Evidence of an unrestricted adaptive capacity. FEBS Lett 327: 297-300. [Crossref]

87. Windisch A, Gundersen K, Szabolcs MJ, Gruber H, Lømo T (1998) Fast to slow transformation of denervated and electrically stimulated rat muscle. J Physiol 510: 623-632. [Crossref]

88. Eken T, Gundersen K (1988) Electrical stimulation resembling normal motor-unit activity: effects on denervated fast and slow rat muscles. $J$ Physiol 402: 651-669. [Crossref]

89. Hennig R, Lømo T (1985) Firing patterns of motor units in normal rats. Nature 314: 164-166. [Crossref]

90. Hepple RT, Rice CL (2016) Innervation and neuromuscular control in ageing skeletal muscle. J Physiol 594: 1965-1978. [Crossref]

91. Lewis DM, al-Amood WS, Schmalbruch H (1997) Effects of long-term phasic electrical stimulation on denervated soleus muscle: guinea-pig contrasted with rat. J Muscle Res Cell Motil 18: 573-586. [Crossref]

92. Simoneau JA, Pette D (1988) Species-specific effects of chronic nerve stimulation upon tibialis anterior muscle in mouse, rat, guinea pig, and rabbit. Pflugers Arch 412: 86-92.

93. Holloszy JO, Booth FW (1976) Biochemical adaptations to endurance exercise in muscle. Annu Rev Physiol 38: 273-291. [Crossref]

94. McDonagh MJN, Davies CTM (1987) Adaptive responses of mammalian skeletal muscle to exercise with high loads. Eur J Appl Physiol 56: 178-198.

95. Baar K, Esser K (1999) Phosphorylation of p70(S6k) correlates with increased skeletal muscle mass following resistance exercise. Am J Physiol 276: C120-127. [Crossref]

96. Lopez-Guajardo A, Sutherland H, Jarvis JC, Salmons S (2001) Induction of a fatigueresistant phenotype in rabbit fast muscle by small daily amounts of stimulation. $J$ Appl Physiol (1985) 90: 1909-1918. [Crossref]

97. Patel TJ, Cuizon D, Costello OM, Fridén J, Lieber RL (1998) Increased oxidative capacity does not protect skeletal muscle fibers from eccentric contraction- induced injury. Am J Physiol 274: R1300-R1308. [Crossref]

98. Hoover F, Kalhovde JM, Dahle MK, Skalhegg B, Tasken K, et al. (2002) Electrical muscle activity pattern and transcriptional and posttranscriptional mechanisms regulate PKA subunit expression in rat skeletal muscle. Mol Cell Neurosci 19: 125-137. [Crossref]
99. Nader GA, Esser KA (2001) Intracellular signaling specificity in skeletal muscle in response to different modes of exercise. J Appl Physiol (1985) 90: 1936-1942. [Crossref]

100. Pallafacchina G, Calabria E, Serrano AL, Kalhovde JM, Schiaffino S (2002) A protein kinase B-dependent and rapamycin-sensitive pathway controls skeletal muscle growth but not fiber type specification. Proc Natl Acad Sci USA 99: 9213-9218. [Crossref]

101. Serrano AL, Murgia M, Pallafacchina G, Calabria E, Coniglio P, et al. (2001) Calcineurin con- trols nerve activity-dependent specification of slow skeletal muscle fibers but not muscle growth. Proc Natl Acad Sci USA 98: 13108-13113. [Crossref]

102. Bezakova G, Rabben I, Sefland I, Fumagalli G, Lomo T (2001) Neural agrin controls acetylcholine receptor stability in skeletal muscle fibers. Proc Natl Acad Sci USA 98: 9924-9929. [Crossref]

103. Hnik P, Skorpil V, Vyklicky L (1962) Diagnosis and therapy of denervation muscle atrophy, in Gutmann E (Ed): The denervated muscle. Prague, Publishing House of Czechoslovak Academy of Science 433-466.

104. Mokrusch T, Engelhardt A, Eichhorn KF, Prischenk G, Prischenk H, et al. (1990) Effects of long-impulse electrical stimulation on atrophy and fibre type composition of chronically denervated fast rabbit muscle. J Neurol 237: 29-34. [Crossref]

105. Valencic V, Vodovnik L, Stefancic M, Jelnikar T (1986) Improved motor response due to chronic electrical stimulation of denervated tibialis anterior muscle in humans. Muscle Nerve 9: 612-617. [Crossref]

106. al-Amood WS, Lewis DM, Schmalbruch H (1991) Effects of chronic electrical stimulation on contractile properties of long-term denervated rat skeletal muscle. $J$ Physiol 441: 243-256. [Crossref]

107. Schmalbruch H1, al-Amood WS, Lewis DM (1991) Morphology of long-term denervated rat soleus muscle and the effect of chronic electrical stimulation. $J$ Physiol 441: 233-241. [Crossref]

108. Kern H, Hofer C, Mödlin M, Forstner C, Raschka-Högler D, et al. (2002) Denervated muscles in humans: limitations and problems of currently used functional electrical stimulation training protocols. Artif Organs 26: 216-218. [Crossref]

109. Graupe D, Cerrel-Bazo H, Kern H, Carraro U (2008) Walking performance, medical outcomes and patient training in FES of innervated muscles for ambulation by thoracic-level complete paraplegics. Neurol Res 30: 123-130. [Crossref]

110. Franceschini M, Cerrel Bazo H, Lauretani F, Agosti M, Pagliacci MC (2011) Age influences rehabilitative outcomes in patients with spinal cord injury (SCI). Aging Clin Exp Res 23: 202-208. [Crossref]

111. Huang H, Sun T, Chen L, Moviglia G, Chernykh E, et al. (2014) Consensus of clinical neurorestorative progress in patients with complete chronic spinal cord injury. Cell Transplant 23 Suppl 1: S5-17. [Crossref]

112. Edmunds KJ, Árnadóttir Í, Gíslason MK, Carraro U, Gargiulo P (2016) Nonlinear Trimodal Regression Analysis of Radiodensitometric Distributions to Quantify Sarcopenic and Sequelae Muscle Degeneration. Comput Math Methods Med 2016: ID 8932950

113. Edmunds KJ, Gargiulo P (2015) Imaging Approaches in Functional Assessment of Implantable Myogenic Biomaterials and Engineered Muscle Tissue. Eur J Transt Myol 25: 4847. [Crossref]

114. Zampieri S, Pietrangelo L, Loefler S, Fruhmann H, Vogelauer M, et al. (2014) Lifelong Physical Exercise Delays Age-Associated Skeletal Muscle Decline. J Gerontol A Biol Sci Med Sci 70: 163-173

115. Nieman K, Hoffmann U (2015) Cardiac computed tomography in patients with acute chest pain. Eur Heart J 36: 906-914. [Crossref]

116. Edmunds KJ, Gargiulo P (2015) Imaging Approaches in Functional Assessment of Implantable Myogenic Biomaterials and Engineered Muscle Tissue. Eur J Transl Myol 25: 4847. [Crossref]

117. Edmunds KJ, Gíslason MK, Arnadottir ID, Marcante A, Piccione F, et al. (2016) Quantitative Computed Tomography and Image Analysis for Advanced Muscle Assessment. Eur J Transl Myol 26: 6015. [Crossref]

118. Carraro U, Edmunds KJ, Gargiulo P (2015) 3D false color computed tomography for diagnosis and follow-up of permanent denervated human muscles submitted to home-based Functional Electrical Stimulation. Eur J Transl Myol 25: 5133. [Crossref]

119. Gargiulo P, Reynisson PJ, Helgason B, Kern H, Mayr W, et al. (2011) Muscle, tendons, and bone: structural changes during denervation and FES treatment. Neurol Res 33 750-758. [Crossref]

120. Edmunds KJ, Gíslason MK, Arnadottir ID, Marcante A, Piccione F, et al. (2016) 
Marcante A (2017) Modulation of trophism and fiber type gene expression in denervated muscle activated by different patterns of electrical stimulation. Role of muscle fiber regeneration revisited in 2017

Quantitative Computed Tomography and Image Analysis for Advanced Muscle Assessment. Eur J Transl Myol 26: 6015. [Crossref]
121. Carraro U, Gava K, Baba A, PiccioneF, Marcante A (2016) Fighting muscle weakness in advanced aging by take-home strategies: Safe anti-aging full-body in-bed gym and functional electrical stimulation (FES) for mobility compromised elderly people. Biol Eng Med 1: 1-4. [Crossref]

Copyright: $\mathbb{0} 2017$ Marcante A. This is an open-access article distributed under the terms of the Creative Commons Attribution License, which permits unrestricted use, distribution, and reproduction in any medium, provided the original author and source are credited. 